\title{
Clinical self-efficacy and illness beliefs in ambiguous chronic pain conditions: General Practitioners' management of Fibromyalgia
}

\author{
María-Ángeles Pastor ${ }^{1 *}$, Sofía López-Roig, Marie Johnston ${ }^{2}$, Rafael Gracia ${ }^{3}$, Pablo Daza ${ }^{3}$ \\ ${ }^{1}$ Departamento de Psicología de la Salud. Universidad Miguel Hernandez. (Spain) \\ 2 Aberdeen Health Psychology Group. Institute of Applied Health Sciences. University of Aberdeen (United Kingdom) \\ ${ }^{3}$ Osakidetza. Servicio V asco de Salud (Spain)
}

\begin{abstract}
Título: Autoeficacia clínica y creencias sobre la enfermedad en problemas de dolor crónico: El manejo de la Fibromialgia en médicos de Atención Primaria.

Resumen: Objetivos: En problemas de dolor crónico, el comportamiento de los profesionales puede estar influido por sus conocimientos científicos y por sus creencias sobre la enfermedad. Nuestro objetivo es identificar las creencias sobre la Fibromialgia (representación mental y autoeficacia clínica) de los médicos de atención primaria y estudiar sus relaciones con el manejo del paciente. Método: 208 médicos participantes en talleres de formación sobre Fibromialgia, completaron una versión adaptada del "Brief Illness Perception Questionnaire" y diferentes medidas de autoeficacia clínica, conducta clínica y satisfacción. Realizamos correlación de Pearson, regresión múltiple, pruebas t y ANOVA. Resultados: La Fibromialgia se consideró un problema importante, con poco control sobre él y asociado a causas psicológicas; la autoeficacia clínica fue moderada. Los componentes de la representación mental predijeron el manejo clínico, aunque con bajos porcentajes de varianza explicada (entre $3 \%$ y $11 \%$ ) mientras que la autoeficacia clínica predijo la satisfacción con el manejo (entre $46 \%$ y $61 \%$ ). Conclusiones: Es necesario incrementar la percepción de control y de autoeficacia de los médicos de atención primaria. Mientras que la fibromialgia siga siendo un problema ambiguo, las variaciones en las cogniciones de los profesionales serán importantes en el tipo de cuidado que recibe el paciente.

Palabras clave: autoeficacia clínica; representación mental; médicos de
\end{abstract} atención primaria; fibromialgia; manejo del paciente.

\section{Introduction}

In ambiguous clinical conditions without clinical objective tests, the physicians' behaviour could be affected not only by scientific knowledge of disease but also by their own beliefs about illness (Parsons et al., 2007). Professionals have their own ideas about particular diseases (Album \& Westin, 2008; Haugli, Strand \& Finset, 2004). In chronic musculoskeletal conditions with no clear pathophysiological explanation, high uncertainty, lack of effective cure and high prevalence of emotional problems, health professionals develop their own beliefs together with their professional issues, which can be related to clinical decisions (Foster et al., 2003; Parsons et al., 2007; Taylor, 2003). Attitudes and beliefs of Health Care Practitioners are related to their self-reported clinical practice in Low Back Pain (Bishop, Foster, Thomas \& Hay, 2008; Coudeyre et al., 2006; Houben et al., 2005) but little is known about other prevalent syndromes such as Fibromyalgia (FM). There is insufficient knowledge of FM causes and the ambiguity of the problem extends the process of diagnosis. Although in the 1990s FM was recognized as a

Dirección para correspondencia [Correspondence address]: $\mathrm{M}^{\mathrm{a}}$ Angeles Pastor. Dpto. Psicología de la Salud. Campus de San Juan. UMH. Ctra. Alicante-Valencia, km.8,7. 03550 Alicante (Spain). E-mail: mapastor@umh.es
Abstract: Aims: In ambiguous chronic pain conditions, professional behaviour may be affected not only by scientific knowledge but also by beliefs about illness. In Spain, Fibromyalgia is the most frequent cause of chronic pain at Primary Care level. Our aims are to identify General Practitioners' beliefs about Fibromyalgia, in terms of mental representation and clinical self-efficacy, and to study their relationships with patient management. Methods: 208 General Practitioners recruited on a voluntarily basis while attending educational workshops on Fibromyalgia, completed an adapted version of the Brief Illness Perception Questionnaire and ad hoc scales of clinical self-efficacy, clinical behaviour and satisfaction. Pearson correlation, multiple regression, $t$ test and ANOVA were performed. Results: Doctors see Fibromyalgia as a severe condition and they perceived low control and moderate clinical self-efficacy. The main causes of Fibromyalgia were seen to be psychological. Regression analysis showed that mental representation components predicted clinical management with low explained variance (from $3 \%$ to $11 \%$ ) while clinical selfefficacy predicted satisfaction with clinical management (from $46 \%$ to 61\%). Conclusions: GPs self-efficacy and control perception of Fibromyalgia need to be enhanced. While FM continues to be an ambiguous condition, variations in clinicians' cognitions will be important for the care patients receive.

Key words: clinical self-efficacy; mental representation; general practitioners; fibromyalgia; patient management.

disease by WHOM, it is still surrounded by controversy. Moreover, new diagnostic criteria have recently been proposed (Wolfe et al., 2010).

Evidence suggests that clinical behaviour can be predicted from well established psychological models, such as Leventhal's Common Sense Self-Regulation Model (CSSRM) (Leventhal et al., 1997) and Social Cognitive Theory (SCT) (Bandura, 1997). This has been shown in health conditions with less uncertainty than FM and where there is an evidence base for clinical practice (Bonetti et al., 2006; Bonetti et al., 2010; Eccles et al., 2007).

CS-SRM (Leventhal et al., 1997) offers a theoretical framework for organizing health cognitions. It proposes that stimuli (FM in this case) generate both cognitive and emotional representations. The cognitive illness representation includes five dimensions (Cameron \& Leventhal, 2003): Identity (label and symptoms of the disease), cause (beliefs about the causes of the illness), timeline (the duration of the illness), consequences (beliefs about illness effects and outcomes) and control (beliefs about illness cure or control). The emotional representation considers reactions such as fear, anger, and distress (Broadbent, Petrie, Maina \& Weinman, 2006). The model has been studied in FM patients (Glattacker, Opitz \& Jäckel, 2010; Van Ittersum, Van Wilgen, Hilberdink, Groothoff \& van der Schan, 2009) but, 
to our knowledge, it has never been applied to professionals' behaviour with these patients.

From SCT (Bandura, 1997), self-efficacy constitutes cognitions relevant to behaviour in a health context. Selfefficacy is defined as beliefs about one's own capabilities to organise and execute actions to obtain desired results. Little is known about physicians' perceptions of their clinical selfefficacy in chronic conditions with high ambiguity. In particular, FM management, with chronic pain of uncertain origin, together with the lack of cure and with no objective tests to support diagnosis, presents a problem for professionals and may challenge their self-efficacy. FM often creates conflictive clinical situations (Belenguer, Ramos-Casals \& Rivera, 2009; Rivera, 2004). Patients express disappointment and unfulfilled expectations with their medical care experience (Harding, Parsons, Rahman \& Underwood, 2005) and consult a wide range of professionals with relative little success (Foster et al., 2003). Physicians experience difficulties in managing what they feel are great demands and expectations from patients (Lambert et al., 2000). Pain management and clinical interaction are complicated for both patients and physicians (Asbring \& Narvanen, 2003; Dobkin et al., 2003; Haugli et al., 2004; Parsons et al., 2007; Werner \& Malterud, 2003). These factors may have consequences for the physicians' clinical self-efficacy in both technical and interpersonal dimensions of medical practice.

In Spain, Primary Care is recommended for FM patients (Ministerio de Sanidad y Política Social, 2011) who represent from $5 \%$ to $8 \%$ of the Primary Care consultations, and FM is the most frequent cause of chronic pain at this level (Carmona et al., 2001). FM is characterized by widespread pain, soft tissue tenderness, fatigue, sleep disturbances and psychological comorbidity. There is insufficient knowledge of FM causes, absence of an objective test for diagnosis and high variability in reported symptoms. Clinical guides tend to include several recommendations based on expert consensus (Carville et al., 2008; Goldenberg, Burckhardt \& Crofford, 2004; Rivera et al., 2006). As in other chronic pain syndromes, FM shows a particular clinical situation far from the traditional biomedical approach. GPs and patients have reported frustration and dissatisfaction dealing with the problem (Ruiz-Moral et al., 2006). FM has low prestige for health personnel (Album \& Westin, 2008) however it may also constitute a challenge for physicians because they are mainly trained to deal with clearly defined diseases (Bieber et al., 2006).

Due to the identified FM characteristics, we propose that the above mentioned theoretical models offer conceptual frameworks to study the GPs' cognitions and their relationships with the clinical management of FM and the GPs' satisfaction with their clinical behaviour. Therefore, our aims were: 1. To explore GP's mental representations of FM and clinical self-efficacy for the management of FM, and the relationships between these cognitions; 2 . To identify the contribution of these cognitions for predicting GPs' behaviours and satisfaction in managing FM.

\section{Materials and Methods}

\section{Participants}

Participants were 210 GPs who took part in 16 workshops on FM in the Basque Health Service and in the 28th and 29th Annual Conferences of the Spanish Society of Family and Community Medicine. Two participants were rejected because they did not answer all items. Of the 208 GPs participants, the majority were women $(64.4 \%: n=134)$, aged $25-62$ years ( $M=45.4$ years; $S D=8.2$ years). They had been working as GPs an average of 17.4 years $(S D=8.9$ years) and attended an average of 1587.5 patients per year $(S D=548.2)$. The average number of FM patients per year attended by GPs was $14(S D=24$; Range $=0-208)$ and the average of consultations per year for each FM patient was 12.7 $(S D=8.1)$. The average of each FM consultation duration was 15.3 minutes ( $S D=6.5$ minutes; Range $=5-45$ minutes). No significant differences between men and women were found at $p \leq .01$ on any variable.

\section{Measures}

\section{Socio-demographic and clinical experience variables}

Participants completed a questionnaire reporting gender and age, professional experience (years working as GP and estimated total number of patients per year), FM experience (calculated as the product of the total number of FM patients per year, estimated number of consultations for each FM patient per year and estimated duration of each FM consultation) and relative FM experience (calculated by dividing the total number of FM patients per year by the total number of patients per year x 100).

\section{FM Mental Representation}

The "Brief Illness Perception Questionnaire" (BIPQ) (Broadbent et al., 2006) was adapted for use with health professionals. The original version was translated and backtranslated by two bilingual people. The agreement was total. In the BIPQ, each mental representation dimension is measured by a single item answered on a scale from 0 to 10 , where the meaning of each extreme varies. Each item assesses one illness perception dimension: Identity, Consequences, Timeline, Personal Control, Treatment Control, Concern, Understanding, Emotional Response and Causes.

Our instruction was 'For the following questions, please circle the number that best corresponds to your views about Fibromyalgia' and the words 'your illness' in each item were changed to 'this illness'. In the first item, '... affect your life" was changed to '.. affect the patients' life'.

The Emotional Response item incorporates only negative reactions; however it is possible that professionals perceived FM as stimulating (Asbring \& Narvanen, 2003). Therefore, a new item, named 'Positive emotional response' 
was included (How much this illness activates you emotionally, is it a challenge, a stimulus?).

In relation to Cause dimension, due to the exploratory character of this study, the Cause subscale of the IPQ-R (Moss-Morris et al., 2002) was combined with the open question on the three main causes attributed to the illness from the BIPQ. In a Likert format $(1=$ totally disagree, $5=$ totally agree) GPs indicated their agreement or disagreement with 18 possible causes for FM and, finally, they rankordered the three most important factors that they believed to cause FM.

\section{Clinical self-efficacy in managing FM}

Two dimensions of clinical practice were considered: technical and interpersonal management. In both cases, professionals used an 11 point numerical rating scale $(0=$ not at all, $10=$ totally) to answer: How confident are you about providing effective medical care to FM patients? and How confident are you about managing the interpersonal relationships with FM patients? The two items correlated $(r=.68 ; p$ $\leq .001)$ and a total score for clinical self-efficacy was calculated by adding the scores (rank from 0 to 20). High scores indicate more FM clinical, technical and interpersonal selfefficacy.

\section{Patient management variables and satisfaction in managing FM}

Participants completed a questionnaire reporting:

Referrals

Patient Referrals: the total percentage of FM patients they usually referred to other professionals.

Service Referrals: GPs rank ordered their frequency of referrals to up to seven different specialties (Trauma, Rheumatology, Psychology, Pain Unit, Neurology, Rehabilitation, and Others). The total number of referral specialties was obtained (from 0 to 7 ).

Referrals for Diagnosis, for Comorbidity and for Treatment: For each specialty, the reasons for referring were requested from three main options: Diagnosis, Comorbidity and Treatment. GPs could choose several reasons for each referral service. The total number of each of these three main reasons over all specialities was obtained (from 0 to 21).

\section{Diagnostic Tests}

In an open question, we asked: 'Please, write in a frequency rank-order the diagnostic tests that you usually request for these patients'. Two GPs classified separately the responses into categories: Recommended, non-recommended tests for FM diagnosis. The recommendations from the Spanish Society of Rheumatology (Rivera et al., 2006) were used as external validity criteria. There was complete agreement. Three vari- ables were obtained: the total number of requests for recommended tests, for non-recommended tests and the total number of tests usually requested.

\section{Prescriptions}

GPs were asked to write in a frequency rank-order the medication and doses that they usually prescribed for these patients [in terms of generic or commercial names]. There was no limit on the number of prescriptions and the GPs could put several prescriptions in the same rank order. Two GPs classified prescriptions according to the drug category (anti-inflammatory, analgesic, etc), the active component (ibuprofen, paracetamol, etc) and classified them as Recommended Prescriptions (where studies support their use), Proscribed Prescription (where studies do not support their use) and Other Prescriptions (where there are no studies). There was complete agreement. Two expert consensus documents for FM were considered as external validity criteria: SER (Rivera et al., 2006) and EULAR (Carville et al., 2008). The total number of each of the three variables was calculated.

\section{Satisfaction}

Perceived satisfaction with the technical management and with the interpersonal management was registered on a scale from $0-10(0=$ not at all, $10=$ totally $)$. The two items correlated $(\mathrm{r}=.62 ; p \leq .001)$ and therefore a total score (rank $0-20)$ was obtained. Higher scores indicate higher satisfaction.

\section{Procedure}

This was a cross-sectional study. GPs were recruited on a voluntarily basis. Nobody refused to participate in the research. Anonymity was guaranteed. Before starting the workshop, they completed a self-administered questionnaire including the study variables.

\section{Statistical Analysis}

SPSS 18.0 was used. Descriptive statistics, $t$-test and Pearson's correlation were performed (using $p \leq .01$ because Bonferroni correction is highly conservative). ANOVA was conducted to explore differences in clinical management considering more than two groups. Multiple regression was used to identify predictors of clinical behaviour where more than one variable showed significant correlations with the same patient management behaviour or satisfaction variables. We tested regression model requirements for no colinearity (condition indices below 30) and for independence (Durbin-Watson between 1.5 and 2.5).

Principal component analysis with Varimax rotation was used for the BIPQ items and for Causal Attribution subscale. Components were included with eigenvalues greater than 1. Items which loaded greater than .50 onto one factor 
were maintained (Moss-Morris et al., 2002) and those which loaded onto more than one factor or which did not appear to load on any of the factors were deleted. A second analysis was conducted with remaining items. The identified components were used for correlation and regression analysis.

\section{Results}

What are GPs' mental representations of FM?

Descriptive of BIPQ items is in Figure 1. Personal control received the lowest rating. Men scored higher than women in 'Positive Emotional Response' $(t=2.6, p \leq .01)$ and no significant relationships were obtained with age.

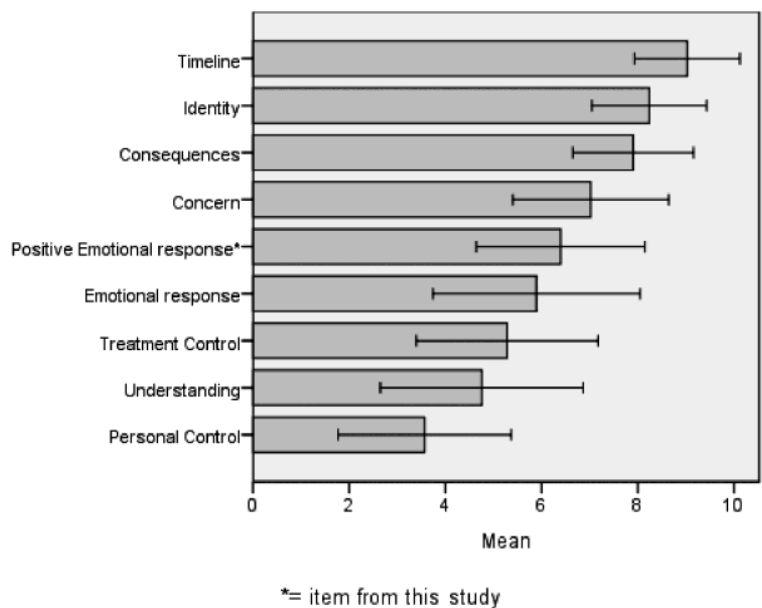

Figure 1: GPs' Mental representations of Fibromyalgia

Three components of the GPs' mental representations, which accounted for $62.7 \%$ of variance, were identified and named 'Controllability', 'Illness Severity' and 'Emotional Representation' $(32.3 \%, 18.1 \%$ and $12.3 \%$ of explained variance, respectively). However, the internal consistency of the 'Emotional Representation' was higher without the Emotional Response item (Table 1). Therefore, we decided to retain the original 'Emotional Response' item separately and the other component was named 'Emotional Engagement' $(\alpha=.65)$. No significant differences by gender or a significant correlation with age was found.

We obtained four causal factors which accounted for $58 \%$ of the variance $(26.11 \%, 16.41 \%, 8.71 \%$ and $7.29 \%$ of explained variance respectively): 'Psychological Attribution' $(\alpha=.82 ; M=27.72 ; S D=3.79)$, 'Risk Factors Attribution' $(\alpha=.82 ; M=10.28 ; S D=3.03)$, 'Biological Attribution' $(\alpha=.76$; $M=5.20 ; S D=1.75)$ and 'Chance Attribution' $(\alpha=.64 ; M=$ 6.86; $S D=2.39)$. No gender differences were found. GPs with longer service in Primary Care attributed FM less to Psychological causes $(r=-.21 ; p \leq .01)$. Furthermore, they attributed FM to Biological causes $(r=.17 ; p \leq .01)$.

With regard to the three main FM causes, 'Personality' was the most common first cause (27.2\%: 41 GPs out of 151 who answered the question) and second cause (25\%: 37 GPs out of 148 who answered the question). Over 60\% of GPs attributed the main causes for FM to psychological factors (personality, stress or worry, emotional states or traumatic life events).

\section{What is GPs' clinical self-efficacy in managing FM?}

Clinical Self-efficacy scores were moderate in all cases (Total clinical Self-efficacy: $M=10.5 ; S D=3.2$; Interpersonal Self-efficacy: $M=5.5 ; S D=1.7$; Technical Self-efficacy: $M=$ $5.0 ; S D=1.8)$. No significant differences were found by gender. Older doctors and those with longer service in Primary Care felt more confident about their interpersonal management of FM patients $(r=.25, p \leq .001 ; r=.18, p \leq .01$, respectively).

Table 1. Mental Representation components from BIPQ items.

1. How much does this illness affect the patient's life?

2. How long do you think this illness will continue?

5. How much do the patients experience symptoms from this illness?

3. How much control do you feel you have over this illness?

4. How much do you think the treatment can help this illness?

7. How well do you feel you understand this illness?

6 . How concerned are you about this illness?

8. How much this illness affects you emotionally? (e.g. does it make you angry, scared, upset or depressed?)

9. How much this illness activates you emotionally, is it a challenge, a stimulus?.

DESCRIPTIVE

Total

Controllability Illness Severit $(\alpha=.69)$

.09

$-.06$

.14

.82

.72

.78

.33

$-.19$

.39

$M(S D)$

$4.5(1.5)$

(1)

$(\alpha=.68$

$\begin{array}{lc}. \mathbf{7 8} & (\alpha-.5) \\ .69 & .15 \\ .77 & -.00 \\ -.17 & .23 \\ .20 & .07 \\ .08 & -.03 \\ .27 & .18 \\ -.01 & .59 \\ & .86 \\ .25 & .65\end{array}$

$*: \alpha=.65$ without item $8 ; * *$ : Descriptive statistic considering items 6 and 9 . 
What is the relationship between mental representations of FM and clinical self-efficacy in managing FM?

Only 'Controllability' and 'Emotional Engagement' mental representation components were significantly correlated to technical $(r=.61, p \leq .001 ; r=22, p \leq .01$, respectively), interpersonal $(r=.50, p \leq .001 ; r=27, p \leq .001$, respectively) and clinical self efficacy total score $(r=.61, p \leq .001 ; r=26, p$ $\leq .001$, respectively). Finally, 'Emotional Representation' was significantly and negatively correlated to perceived technical self-efficacy $(r=-.19 ; p \leq .01)$.

Do professional experience and cognitions predict patient management and satisfaction?

Professional experience, patient management and satisfaction.- GPs with longer service in Primary Care referred more for Diagnosis $(r=.18 ; \mathrm{p} \leq .01)$ and less for Comorbidity $(\mathrm{r}=$ $.24 ; \mathrm{p} \leq .001)$ and Treatment $(\mathrm{r}=-.19 ; \mathrm{p} \leq .01)$. GPs with more patients referred less for Comorbidity and Treatment $(\mathrm{r}=-.18 ; \mathrm{p} \leq .01)$ in both cases. GPs with more experience in FM referred a lower percentage of patients to other services $(\mathrm{r}=-.22 ; \mathrm{p} \leq .01)$. Relative FM experience was correlated with referral for Treatment $(\mathrm{r}=.27 ; \mathrm{p} \leq .001)$ and nonrecommended tests $(r=.24 ; \mathrm{p} \leq .01)$. GPs with longer service in Primary Care reported more satisfaction with their FM interpersonal management $(\mathrm{r}=.18 ; \mathrm{p} \leq .01)$.

Cognitions, patient management and satisfaction.- Correlation analysis showed significant relationships between cognitions and four out of eleven patient management variables (Table 2). In relation to MR components, Controllability was significantly correlated with Patient Referrals $(r=-.24 ; p \leq .01)$ and Treatment Referrals ( $r=-.18 ; p \leq .01)$ and Illness Severity with Comorbidity Referrals $(r=.19 ; \mathrm{p} \leq .01)$ and Nonrecommended Tests $(r=.22 ; \mathrm{p} \leq .01)$. In relation to the remaining significant correlations, the lowest and highest values were for Clinical Self-efficacy with Patient Referrals ( $r=$ .18) and with Total Satisfaction $(r=.77)$.

Table 2. FM Cognitions, Clinical behavior and Satisfaction ${ }^{\mathrm{a}}$

\begin{tabular}{|c|c|c|c|c|c|c|c|}
\hline & Controllability & $\begin{array}{l}\text { Illness } \\
\text { Severity }\end{array}$ & $\begin{array}{c}\text { Emotional } \\
\text { Engagement }\end{array}$ & $\begin{array}{l}\text { Emotional } \\
\text { Response }\end{array}$ & $\begin{array}{c}\text { Technical } \\
\text { Self-efficacy }\end{array}$ & $\begin{array}{c}\text { Interpersonal } \\
\text { Self-efficacy }\end{array}$ & $\begin{array}{c}\text { Clinical } \\
\text { Self-efficacy }\end{array}$ \\
\hline Patient Referrals & $-.24 * *$ & .03 & -.08 & .04 & $-.20 * *$ & -.12 & $-.18^{* *}$ \\
\hline Comorbidity Referrals & -.16 & $.19 * *$ & .03 & .03 & -.11 & -.08 & -.10 \\
\hline Treatment Referrals & $-.18^{* *}$ & .12 & .02 & .08 & -.13 & -.14 & -.15 \\
\hline Non-recommended Tests & .01 & $.22 * *$ & .08 & .13 & -.03 & -.05 & -.04 \\
\hline Technical management Satisfaction & $.63^{* * *}$ & .15 & .17 & -.13 & $.69 * * *$ & $.67 * * *$ & $.75^{* * *}$ \\
\hline Interpersonal management Satisfaction & $.43 * * *$ & .12 & $.23 * *$ & $-.18^{* *}$ & $.51 * * *$ & $.68^{* * *}$ & $.65^{* * *}$ \\
\hline Total Satisfaction & $.51 * * *$ & .15 & $.22 * *$ & -.17 & $.66^{* * *}$ & $.65^{* * *}$ & $.77 * * *$ \\
\hline
\end{tabular}

a: Referral services number, Diagnostic referral, Recommended tests, Total tests, Total Prescriptions, Recommended Prescriptions,

Proscribed prescriptions, excluded because no significant relationship with any cognition variable at significant level established; ${ }^{* *}: p \leq .01 ;{ }^{* * *}: p \leq .001$

The sample was divided into three groups based on the first option chosen as a main cause. GPs who attributed FM to stable psychological traits (Personality), GPs who attributed FM to situational psychological factors (stress or worries, emotional states and mental attitude) and GPs who attributed FM to any other non-psychological factor (virus, chance, immunity problems, hereditary, among others) were compared on their clinical behaviour and satisfaction. Significant differences were obtained in:

- Referral for Diagnosis $(F=3.02 ; p=.05)$ : GPs that attributed FM to psychological situational factors referred more for diagnosis $(M=0.82 ; S D=0.89)$ than those attributing FM to personality $(M=0.43 ; S D=0.50)$.

- Total Tests $(F=3.53$; $p=.03)$ : GPs who attributed FM to non-psychological factors requested more tests for diagnosis $(M=2.54 ; S D=1.07)$ than those who attributed FM to psychological situational factors $(M=2.02 ; S D=1.07)$.

- Total Prescriptions $(F=3.85 ; p=.02)$ : GPs attributed FM to non-psychological factors prescribed more drugs $(M=3.28 ; S D=1.61)$ than those who attributed FM to Personality $(M=2.36 ; S D=1.75)$.
Table 3 shows the patient management predictors. The proportion of variance explained for each patient management variable ranged from $3 \%$ for Total Tests to $11 \%$ for Non-recommended Tests. For patient referrals and referral for treatment, the significant predictors were professional experience variables whereas for referral for comorbidity, total tests and total prescriptions, the predictors were mental representation variables (Table 3). The use of nonrecommended tests was predicted by a combination of relatively greater FM experience and greater perceived illness severity.

Cognitions, mainly those related to clinical self-efficacy were significant predictors of the satisfaction variables (Table 4). The proportion of variance explained ranged from $46 \%$ for satisfaction with the FM interpersonal management to $61 \%$ for total satisfaction. 
Table 3. Patient management predictors (significant predictors in italics).

\begin{tabular}{|c|c|c|c|c|c|}
\hline Patient Management & Predictors & $\beta$ & $\mathrm{R}^{2}$ & $F$ & df \\
\hline \multirow[t]{3}{*}{ Patient Referrals } & FM experience & $-.22(.02)$ & .06 & $3.80(.01)$ & 3,121 \\
\hline & Controllability & -.20 & & & \\
\hline & Technical Management Self-efficacy & .02 & & & \\
\hline \multirow[t]{3}{*}{ Referral for Comorbidity } & Time in Primary Care & -.07 & .06 & $3.17(.02)$ & 4,132 \\
\hline & Number of Patients & .04 & & & \\
\hline & Illness Severity & $.27(.002)$ & & & \\
\hline \multirow[t]{5}{*}{ Referral for Treatment } & Age & -.05 & .10 & $4.74(.001)$ & 4,132 \\
\hline & Number of Patients & .005 & & & \\
\hline & Relative FM experience & $.27(.002)$ & & & \\
\hline & Controllability & -.13 & & & \\
\hline & Time in Primary Care & $-.17(04)$ & & & \\
\hline \multirow[t]{2}{*}{ Total Test } & Situational-No psychology* & $-24(.009)$ & .03 & $3.53(.03)$ & 2,142 \\
\hline & Personality-No psychology & -.13 & & & \\
\hline \multirow[t]{2}{*}{ Non-recommended Tests } & Relative FM experience & $.22(.007)$ & .11 & $8.45(.0001)$ & 2,141 \\
\hline & Illness Severity & $.23(.005)$ & & & \\
\hline \multirow[t]{3}{*}{ Total Prescriptions } & Gender & -.15 & .05 & $3.74(.01)$ & 3,141 \\
\hline & Situational-No psychology* & $-.18(.04)$ & & & \\
\hline & Personality-No psychology & $-.22(.01)$ & & & \\
\hline
\end{tabular}

*=Two dummy variables were created to compare the three causal attribution groups.

Table 4. Satisfaction with the clinical management predictors*.

\begin{tabular}{|c|c|c|c|c|c|}
\hline Dependent Variables & Predictors & $\beta$ & $\mathrm{R}^{2}{ }_{\mathrm{c}}$ & $\mathrm{F}$ & df \\
\hline \multirow[t]{7}{*}{ Interpersonal Management Satisfaction } & Clinical Self-efficacy & $.58(.000)$ & .46 & $22.3(.000)$ & 7, 168 \\
\hline & Controllability & .04 & & & \\
\hline & Emotional Engagement & .07 & & & \\
\hline & Emotional Representation & $-.12(05)$ & & & \\
\hline & Biological Attribution & $.16(.008)$ & & & \\
\hline & Time at Primary Care & .05 & & & \\
\hline & Age & -.06 & & & \\
\hline \multirow{2}{*}{$\begin{array}{l}\text { Technical Management } \\
\text { Satisfaction }\end{array}$} & Clinical Self-efficacy & $.56(.000)$ & .60 & $137.12(.000)$ & 2,183 \\
\hline & Controllability & $.29(.000)$ & .61 & $98.04(.000)$ & 3,181 \\
\hline \multirow[t]{3}{*}{ Total Satisfaction } & Clinical Self-efficacy & $.65(.000)$ & & & \\
\hline & Controllability & $.20(.001)$ & & & \\
\hline & Emotional Engagement & -.03 & & & \\
\hline
\end{tabular}

* Significant predictors in italics

\section{Discussion}

This study aimed to explore GPs' cognitions of FM and their relationships with patient management and satisfaction. The results show that GPs had a wide range of perceptions of FM and of their efficacy in managing FM patients. In general, GPs' mental representation is close to those reported by FM patients (Van Wilgen, Van Ittersum, Kaptein \& Van Wijhe, 2008). They see the condition as having a long timeline with considerable symptoms and consequences for patients. By contrast, they consider they have low personal or treatment control over FM and report having low understanding of it. It is therefore not surprising that they rate their self-efficacy for dealing with FM as only moderate. Furthermore this is true for both technical and interpersonal management.

Satisfaction in managing FM patients was also moderate but lower for technical than for interpersonal aspects of management. These results support previous findings that physicians are unhappy with the care they provide (Foster et al., 2003; Lambert et al., 2000).

While previous studies have investigated individuals' selfefficacy for specific behaviors (Bandura, 1997) or general self-efficacy (Schwarzer, 1992), the current study focused on clinical self-efficacy, in managing FM patients, investigating how this related to GPs cognitions about FM and their clinical behaviors. Clinical self-efficacy was primarily related to the perceived controllability of FM, with high correlations (Cohen, 1988), but also to positive engagement and to a lesser extent negative emotions associated with FM. It was not related to the perceived severity of the illness. Interpersonal self-efficacy was related to positive but not negative emotions i.e. confidence in the management of the interpersonal aspects of the consultation was greater where GPs saw it as a challenge but were unaffected by their distress in dealing with FM. However, GPs with high technical self-efficacy, 
perceived FM as producing less negative emotions such as depression or anger. These relationships suggest that the technical management, and not the interpersonal management, is the component associated with doctors' perceptions of FM patients as unpopular (Album \& Westin, 2008). In general, professional experience was not associated with GPs' clinical self-efficacy. This result makes theoretical sense because more professional experience does not necessarily imply mastery experiences in FM care, one of the sources of self-efficacy.

Personal and professional background did not relate to the GPs' mental representation. Similar results were obtained in FM patients (Glattacker et al., 2010; Stuifbergen, Phillips, Voelmeck \& Browder, 2006). The main causes of FM were seen to be psychological; although risk factors such as age, accident or injury, and biological causes (virus, immunology problems) were also endorsed. The main explanations of the causes of FM did not associate with clinical self-efficacy. However they did predict, to a very low extent, clinical management. In previous studies, stress and overwork were the most frequent causes proposed by FM patients (Glattacker et al., 2010; Stuifbergen et al., 2006) but other authors have shown that most FM patients attributed their illness to external somatic factors (Van Wilgen et al., 2008). The discrepancy between patients' and GPs' causal attributions could affect the clinical interaction and have consequences for satisfaction with the clinical encounters (Parsons et al., 2007; Van Wilgen et al., 2008) or for adherence. More studies comparing professionals' and FM patients' mental representations are needed.

In our study, GPs' management decisions were related to illness cognitions even allowing for clinical experience: referral for comorbidity, total tests ordered, total nonrecommended tests and total prescriptions were all predicted by illness cognitions. More referrals were made for comorbidity if FM was seen as severe and uncontrollable, while fewer tests were ordered if FM was thought to be caused by situational personal factors and there were more prescriptions if the condition was seen to have non-psychological causes. Two factors predicted the use of tests outside the recommended set: more tests were ordered by GPs with greater experience of working with FM patients and who saw the condition as more severe. Thus, GPs cognitions but not their emotional representations, appear to affect their management of FM. Similar results were obtained predicting GPs' behavior in other health problems (Eccles et al., 2010). Although the percentages of explained variance were very low, results are particularly relevant for FM management because, in the Primary Care context, FM direct costs (medical visits, referrals, diagnostic tests and prescriptions) are higher than in other health problems and, specifically, prescriptions and referrals represent the highest cost (Rivera et al., 2009; Sicras-Mainar, Blanca-Tamayo, Navarro-Artieda \& RejasGutiérrez, 2009).
GPs' total and technical satisfaction in managing patients with FM was strongly related to their clinical self-efficacy and to their perceptions that the condition was controllable, with high percentages of explained variance $(61 \%$ and $60 \%)$. These factors were considerably more important than their emotional responses, whether positive or negative. However, in relation to the satisfaction with their interpersonal management of FM patients, those GPs with high clinical selfefficacy and less negative emotional responses and who attributed biological causes for FM reported more satisfaction in this area of patient management. This result is in accordance with the idea that health personnel are more comfortable when health problems fit the biomedical approach (Asbring \& Narvanen, 2003; Bieber et al., 2006).

Thus, consistent with the CS-SRM, GPs' thoughts and actions with respect to FM appear to fall into two categories: emotional responses, which are associated with a feeling of confidence about managing patients but do not predict what GPs actually do, and illness cognitions, which are associated with clinical behaviors (referrals, tests and prescriptions). Leventhal (Leventhal et al., 1997) proposes that when faced with a challenging situation, we have two parallel response modes, one dealing with the problem and the other addressing our emotional response. In patient studies, behaviors which are difficult to explain from a medical understanding of their condition, have been explained in terms of both their perception of the threat associated with the clinical condition and their emotional response to that threat. The evidence presented here suggests that while emotional responses to FM are frequently discussed, they do not appear to impinge on patient management, while cognitive responses do. Finally, increased perception of controllability of illness and personal clinical self-efficacy would have positive consequences in the level of satisfaction with their professional work with FM patients.

The main strengths of this study are: we propose and assess clinical self-efficacy as an important aspect of clinical experience, differentiating technical and interpersonal aspects; we theorize the role of illness perceptions separating cognitive and emotional responses using the CS-SRM; and we relate cognitions to a range of measures of clinical practice and GPs' satisfaction with management of FM patients.

The main weaknesses are: First, the use of self-reporting of clinical behaviors. A wide variety of methods have been used to assess frequencies of clinical behaviors, including self-reporting, observational methods and the use of routinely recorded data e.g. prescription records. However each of these is limited in some way and a systematic review was inconclusive on the validity of methods including selfreporting methods (Hrisos et al., 2009); second, the sample (GPs who attend educational workshops on FM) limits the external validity because they probably have a more positive attitude towards FM than the general population of GPs; third, one might expect some overall bias such as a social desirability response set or a bias in presenting FM in a favorable or unfavorable light, but neither of these response sets 
fits the observed data; clinicians clearly distinguished their emotional responses from the clinical management responses; and, finally, specific causes related to FM were not added. Therefore, biological factors were less numerous in the scale. However, GPs wrote the three main causes in an open format and answers were similar in both means of measurement. Future research should consider these limitations in order to replicate results. Furthermore, we should explore these issues in other professionals as nurses, physiotherapists or rheumatologists.

\section{Conclusions}

The ambiguous nature of FM may be a source of discomfort or distress and low confidence in dealing technically with patients while at the same time resulting in diverse perceptions of the condition. However clinical management is influenced slightly more by these beliefs about the condition than the GPs' emotional responses. Until there are clearer indications about the optimal clinical management, it may be possible to reduce GPs discomfort without affecting technical clinical care. From a patients' point of view, they are likely to receive treatment from doctors who do not feel confident

\section{References}

Album, D. \& Westin, S. (2008). Do diseases have a prestige hierarchy? A survey among physicians and medical students. Social Science \& Medicine, 66, 182-188.

Asbring, P. \& Narvanen, A.L. (2003). Ideal versus reality: physicians' perspectives on patients with chronic fatigue syndrome (CFS) and fibromyalgia. Social Science \& Medicine, 57, 711-20.

Bandura, A. (1997). Self-efficacy: The exercise of control. New York: Freeman.

Belenguer, R., Ramos-Casals, M., \& Rivera, J. (2009). Clasificación de la Fibromialgia. Revisión sistemática de la literatura. Reumatología Clínica, 5, $55-62$.

Bieber, Ch., Mu“ller, K.G., Blumenstiel, K., Schneider, A., Richter, A., Wilke, S., Hartmann, M., \& Eich, W. (2006). Long-term effects of a shared decision-making intervention on physician-patient interaction and outcome in fibromyalgia. A qualitative and quantitative 1 year follow-up of a randomized controlled trial. Patient Education \& Counseling, 63, 357-366

Bishop, A., Foster, N.E., Thomas, E., \& Hay, E.M. (2008). How does the self-reported clinical management of patients with low back pain relate to the attitudes and beliefs of health care practitioners? A survey of UK general practitioners and physiotherapists. Pain, 135, 187-195.

Bonetti, D., Pitts, N., Eccles, M. et al (2006). Applying psychological theory to evidence-based clinical practice: identifying factors predictive of taking intra-oral radiographs. Social Science \& Medicine, 63, 1889-1899.

Bonetti, D., Johnston, M., Clarkson, J. et al. (2010). Applying psychological theory to evidence-based clinical practice: identifying factors predictive of placing preventive fissure sealants. Implementation Science, 5:25 (doi:10.1186/1748-5908-5-25)

Broadbent, E., Petrie, K.J., Maina, J., \& Weinman, J. (2006). The Brief Illness Perception Questionnaire. Journal of Psychosomatic Research, 60, 631637.

Cameron, L. D. \& Leventhal, H. (2003). Self-regulation, health, and illness: An overview. In L. D. Cameron \& H. Leventhal (Eds.), The self-regulation of health and illness behaviour (pp. 1-14). London \& New York: Routledge.

Carmona, L., Ballina, F.J. Gabriel, R., Lafton, A., \& EPISER study group (2001) The burden of musculoskeletal diseases in the general population of Spain: results from nation-wide study. Annals of Rheumatic Diseases, 60, 1040-05 in dealing with their condition and who may find the consultations unsatisfactory; the decisions their doctors make, about referrals, tests and prescribing, are likely to be influenced by the GPs perceptions of FM and this is likely to vary between GPs. While there continues to be ambiguity over the diagnostic criteria for FM, variations in clinicians' beliefs, such as those observed here, will be determinants of the care patients receive. Increased consensus and training in FM would allow GPs to be more efficient with health resources and to improve the process of care for these patients. Finally, GPs self-efficacy should be enhanced. GPs were less distressed by FM if they had more confidence in their technical skills and greater satisfaction with interpersonal management of patients. More satisfaction was experienced by those who had more confidence in their skills.

Acknowledgements.- Sofía López-Roig and $\mathrm{M}^{\mathrm{a}}$ Angeles Pastor received a grant from the Valencian Government (Spain) for a stay with the Aberdeen Health Psychology Group (Projects: BEST/2010/132 and BEST/2010/131. Consellería d’Educació).

Students Silvia Campos, Irene Portilla and Patricia García were involved in data entry.

Carville, S.F., Arendt-Nielsen, S., Bliddal, H. et al (2008). EULAR evidencebased recommendations for the management of fibromyalgia syndrome. Annals of Rheumatic Diseases, 67, 536-541.

Cohen, J. (1988). Statistical power analysis for the behavioral sciences ( $2^{\text {nd }}$ ed). New Jersey: Lawrence Erlbaum Associates.

Coudeyre E, Rannou F, Tubach F, Baron G, Coriat F, Brin S, et al. (2006). General practitioners' fear-avoidance beliefs influence their management of patients with low back pain. Pain, 124, 330-7.

Dobkin, P.L., De Civita, M., Abrahamowicz, M., Bernatsky, S., Schulz, J., Sewitch, M., \& Baron, M. (2003). Patient-physician discordance in fibromyalgia. Journal of Rheumatology, 30, 1326-34.

Eccles, M.P., Grimshaw, J.M., Johnston, M., et al. (2007). Applying psychological theory to evidence-based clinical practice: identifying factors predictive of managing upper respiratory tract infections without antibiotics. Implementation Science, 2:26 (doi:10.1186/1748-5908-2-26).

Foster, N. E., Pincus, T., Underwood, M. R., Vogel, S., Breen, A., \& Harding, $G$ (2003). Understanding the process of care for musculoskeletal conditions - why a biomedical approach is inadequate. Rheumatology, 42, 401-403.

Glattacker, M., Opitz, U., \& Jäckel, W.H. (2010). Illness representations in women with Fibromyalgia. British Journal of Health Psychology, 15, $367-$ 387.

Goldenberg, D.L., Burckhardt, C, \& Crofford, L. (2004). Management of Fibromyalgia Syndrome. JAMA, 292, 2388-2395.

Harding, G., Parsons, S., Rahman, A., \& Underwood, M. (2005). 'It struck me that they didn't understand pain': the specialist pain clinic experience of patients with chronic musculoskeletal pain. Arthritis \& Rheumatism, 53, 691-696.

Haugli, L., Strand, E., \& Finset, A. (2004). How do patients with rheumatic disease experience their relationship with their doctors? A qualitative study of experiences of stress and support in the doctor-patient relationship. Patient Education \& Counseling, 52, 169-174.

Houben, R.M., Ostelo, R., Vlaeyen, J., Wolters, P.M., Peters, M., \& Stompvan den Berg SG. (2005). Health care providers' orientations towards common low back pain predict perceived harmfulness of physical activities and recommendations regarding return to normal activity. European Journal of Pain, 9, 173-83. 
Hrisos, S., Eccles, M.P., Francis, J.J., Dickinson, H.O., Kaner, E.F.S., Beyer, F., \& Johnston, M. (2009). Are there valid proxy measures of clinical behaviour? a systematic review. Implementation Science, 4:37 (doi:10.1186/1748-5908-4-37).

Lambert, B.L., Butin, D.N., Moran, D., et al (2000). Arthritis care: comparison of physicians' and patients' views. Seminars in Arthritis \& Rheumatism, 30, 100-110.

Leventhal, H., Benyamini, Y., Brownlee, S., Diefenbach, M., Leventhal, E., Patrick-Miller, L. \& Robitaille, C. (1997). Illness representations: Theoretical Foundations. In: Petrie, K.J. \& Weinman, J. (Eds.), Perceptions of bealth and illness: Current research and applications (pp. 19-45. Amsterdam: Harwood. Academic Publishers.

Ministerio de Sanidad y Política Social (2011). Fibromialgia. Ed. Ministerio de Sanidad, Política Social e Igualdad. ISBN: 978-84-7670-717-3

Moss-Morris R, Weinman J, Petrie KJ, Horne R, Cameron LD, Buick, D. (2002). The Revised Illness Perception Questionnaire (IPQ-R). Psychology \& Health, 17, 1-16.

Parsons, S., Harding, G., Breen, Foster, N., Pincus, T., Vogel, S, \& Underwood, M. (2007). The Influence of patients' and Primary Care Practitioners' beliefs and expectations about Chronic Musculoskeletal Pain on the process of care. A systematic review of qualitative studies. Clinical Journal of Pain, 23, 91-98.

Rivera, J (2004). Controversias en el diagnóstico de la Fibromialgia. Revista Española de Reumatología, 31, 501-06.

Rivera, J., Alegre, C., Ballina, F.J., Carbonell, J., Carmona, L., Castel, B., Collado, A., Esteve, J.J., Martínez, F.G., Tornero, J, Vallejo, M.A., \& Vidal, J. (2006). Documento de consenso de la Sociedad Española de Reumatología sobre la Fibromialgia. Reumatología Clínica, 2Supl1: S55-66.

Rivera, J., Rejas, J., Vallejo, M.A., Esteve-Vives, J. y Grupo ICAF (2009). Situación laboral y gasto sanitario en pacientes con Fibromialgia. Reumatología Clínica, 5:145 (doi 10.3252/pso.es.35ser.2009).
Ruiz Moral, R., Rodríguez Salvador, J., Pérula, L. et al (2006). Problemas y soluciones en la atención sanitaria de enfermedades crónicas. Un estudio cualitativo con pacientes y médicos. Atención Primaria, 38, 483-489.

Sicras-Mainar, A., Blanca-Tamayo, M., Navarro-Artieda, R., \& RejasGutiérrez, J. (2009). Perfil de uso de recursos y costes en pacientes que demandan atención por fibromialgia o trastorno de ansiedad generalizada en el ámbito de la atención primaria de salud. Atención Primaria, 41, 77-84.

Stuifbergen, A.K., Phillips, L., Voelmeck, W., \& Browder, R. (2006). Illness perceptions and related outcomes among women with fibromyalgia syndrome. Women's Health Issues, 16, 353-360.

Schwarzer, R. (1992). Self-efficacy. Thought control of action. Bristol:Taylor \& Francis.

Taylor, S. E. (2003). Health Psychology (5th ed.). New York: McGraw-Hill.

Van Ittersum, M.W., Van Wilgen, C.P., Hilberdink, W.K.H.A., Groothoff, J.W., \& van der Schans, C.P. (2009). Illness perceptions in patients with fibromyalgia. Patient Education \& Counselling, 74, 53-60.

Van Wilgen, C.P., Van Ittersum, M.W., Kaptein, A.A., \& Van Wijhe, M. (2008). Illness perceptions in patients with Fibromyalgia and their relationship to quality of life and catastrophizing. Arthritis \& R heumatism, 58, 3618-3626.

Werner, A \& Malterud, K. (2003). It is hard work behaving as a credible patient: encounters between women with chronic pain and their doctors. Social Science \& Medicine, 57, 1409-1419.

Wolfe, F., Clauw, D. J., Fitzcharles,M.A., Goldenberg, D., Katz, R.S., Mease, Ph., Russell, A.S., Russell, J., Winfield, J.B., \& Yunus, M.B. (2010). The American College of Rheumatology Preliminary Diagnostic Criteria for Fibromyalgia and Measurement of Symptom Severity. Arthritis Care \& Research, 62, 600-610.

(Article received: 08-04-2011, reviewed: 25-10-2011, accepted: 28-10-2011) 